\title{
Multilevel cervical arthroplasty: current evidence. A systematic review
}

\author{
Andrei F. Joaquim, MD, PhD, ${ }^{1}$ and K. Daniel Riew, MD² \\ 1'Department of Neurology, Discipline of Neurosurgery, State University of Campinas (UNICAMP), Campinas, São Paulo, Brazil; \\ and ${ }^{2}$ Department of Orthopedics, Columbia University, New York, New York
}

OBJECTIVE Cervical disc arthroplasty (CDA) has been demonstrated to be an effective treatment modality for singlelevel cervical radiculopathy or myelopathy. Its advantages over an anterior cervical discectomy and fusion (ACDF) include motion preservation and decreased reoperations at the index and adjacent segments up to 7 years postoperatively. Considering the fact that many patients have multilevel cervical disc degeneration (CDD), the authors performed a systematic review of the clinical studies evaluating patients who underwent multilevel CDA (2 or more levels).

METHODS A systematic review in the MEDLINE database was performed. Clinical studies including patients who had multilevel CDA were selected and included. Case reports and literature reviews were excluded. Articles were then grouped according to their main study objective: 1) studies comparing multilevel CDA versus ACDF; 2) studies comparing single-level CDA versus multilevel CDA; and 3) multilevel CDA after a previous cervical spine surgery.

RESULTS Fourteen articles met all inclusion criteria. The general conclusions were that multilevel CDA was at least as safe and effective as ACDF, with preservation of cervical motion when compared with ACDF and potentially with fewer reoperations expected in most of the studies. Multilevel CDAs are clinically effective as single-level surgeries, with good clinical and radiological outcomes. Some studies reported a higher incidence of heterotopic ossification in multilevel CDA when compared with single-level procedures, but without clinical relevance during the follow-up period. A CDA may be indicated even after a previous cervical surgery in selected cases.

CONCLUSIONS The current literature supports the use of multilevel CDA. Caution is necessary regarding the more restrictive indications for CDA when compared with ACDF. Further prospective, controlled, multicenter, and randomized studies not sponsored by the device manufactures are desirable to prove the superiority of CDA surgery over ACDF as the treatment of choice for CDD in selected cases.

https://thejns.org/doi/abs/10.3171/2016.10.FOCUS16354

KEY WORDS cervical arthroplasty; multilevel; single level; anterior cervical discectomy and fusion; cervical degenerative disc disease

$\mathrm{S}$ INGLE-level cervical disc arthroplasty (CDA) is an acceptable and effective treatment modality for cervical radiculopathy or myelopathy; it has potential advantages over an anterior cervical discectomy and fusion (ACDF), such as preservation of cervical range of motion (ROM) that may decrease clinical adjacent-segment pathology (CASP). ${ }^{9}, 19,25$ Several different FDA-approved devices were evaluated, some of them with 10-year followup, but the vast majority of the papers focused on singlelevel disease., ${ }^{9,19,25,26}$ These devices had different biomechanical characteristics, such as the location of their cores and a constrained or unconstrained nature, among others. ${ }^{5,6,14}$ Considering the fact that many patients had mul- tilevel cervical disc degeneration (CDD), we performed a literature review of the clinical studies involving patients who underwent 2 or more levels of CDA.

\section{Methods}

A systematic review of the literature using the MEDLINE database (National Library of Medicine), without time restriction, was performed on August 1, 2016. The following search strategy was used: ("neck"[MeSH Terms] OR "neck"[All Fields] OR "cervical"[All Fields]) AND ("arthroplasty”[MeSH Terms] OR "arthroplasty"[All Fields]) AND multilevel [All Fields]. This search pro-

ABBREVIATIONS ACDF = anterior cervical discectomy and fusion; CASP = clinical adjacent-segment pathology; CDA = cervical disc arthroplasty; CDD = cervical disC degeneration; $\mathrm{HO}$ = heterotopic ossification; JOA = Japanese Orthopaedic Association; MCS = Mental Component Summary; NDI = Neck Disability Index; ODI = Oswestry Disability Index; PCS = Physical Component Summary; ROM = range of motion; SF-12, SF-36 = 12-Item Short Form Health Survey, 36-Item Short Form Health Survey; VAS = visual analog scale 

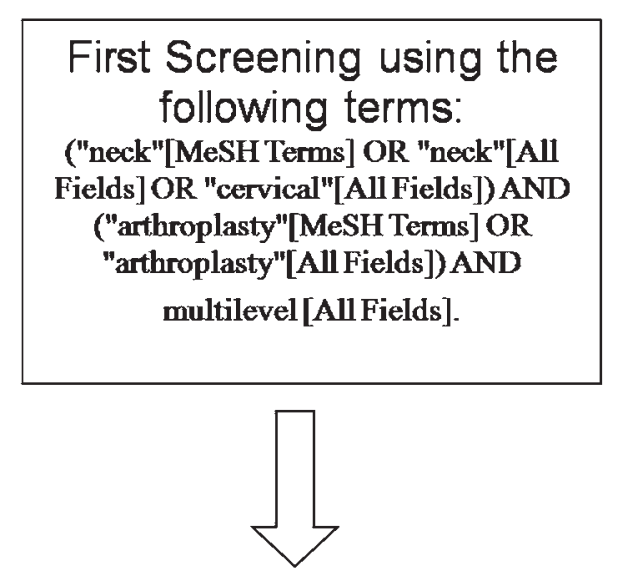
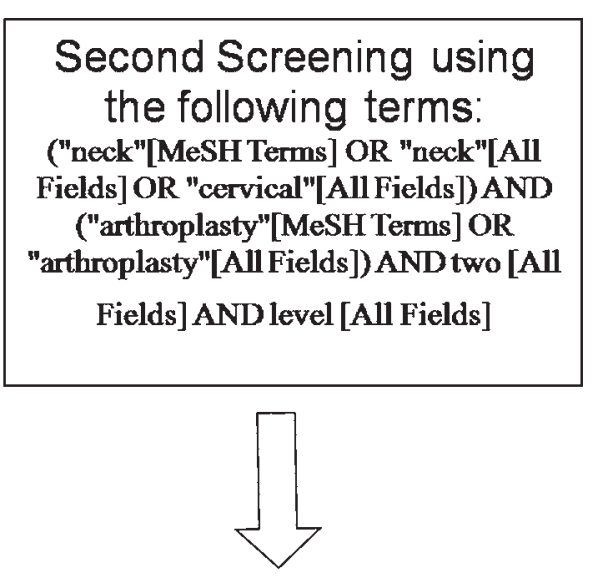

Abstracts of 250 articles were reviewed

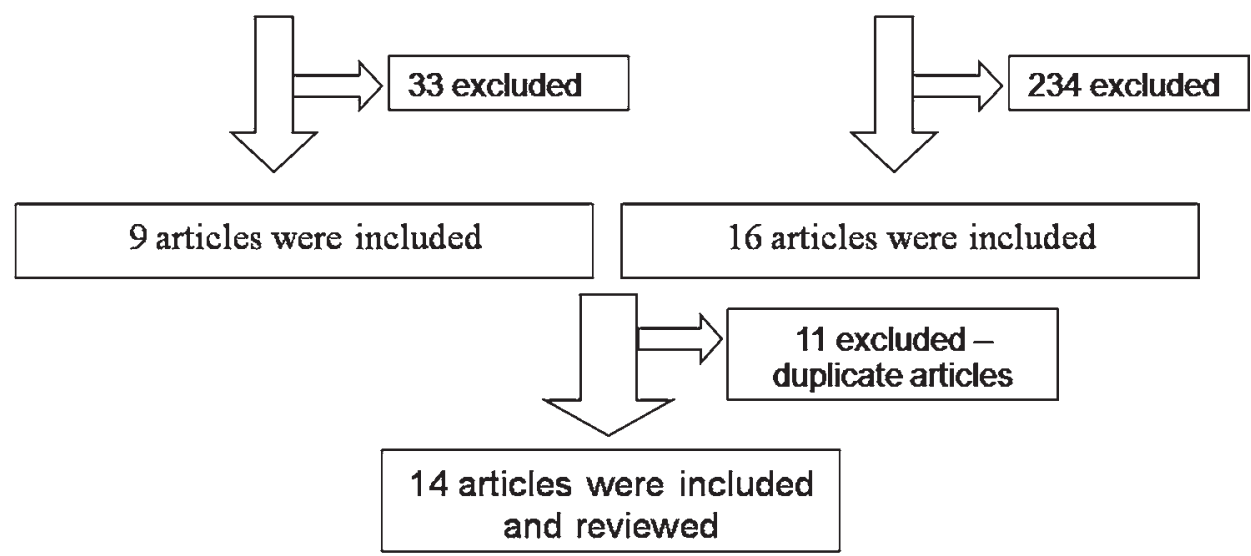

FIG. 1. Flowchart showing the selection process for the papers included in our review, according to our search methodology and inclusion criteria.

duced a total of 42 published articles. We also used an additional search strategy: ("neck"[MeSH Terms] OR "neck"[All Fields] OR "cervical"[All Fields]) AND ("arthroplasty”[MeSH Terms] OR "arthroplasty”[All Fields]) AND two [All Fields] AND level [All Fields]; this search obtained a total of 250 published articles.

After reviewing all the titles and abstracts, we excluded case reports and systematic reviews, including only clinical articles discussing the nuances and surgical results of multilevel CDA (at least 2 levels). After screening the abstracts, we also searched for cross references, with a total of 14 studies included according to the purpose of our review. The articles were evaluated by the first author (A.F.J.). A flowchart was added (Fig. 1) to illustrate our search mechanism and inclusion/exclusion criteria. Articles were then grouped according to the main objective studied: 1) studies comparing multilevel CDA versus $\mathrm{ACDF}$; 2) studies comparing single-level CDA versus multilevel CDA; and 3) multilevel CDA after a previous cervical spine surgery.

\section{Study Quality Assessment}

All studies included in our review were classified according to their level of evidence. We used the criteria proposed by the North American Spine Society (Levels of Evidence for Primary Research Question as Adopted by the North American Spine Society January 2005, accessible at https://www.spine.org/Documents/Research ClinicalCare/LevelsOfEvidence.pdf). These criteria were adapted from the Oxford Centre for Evidence-Based Medicine (OCEBM) Levels of Evidence (http://www.cebm.net/ ocebm-levels-of-evidence/).

\section{Results}

\section{Multilevel CDA Versus ACDF- 5 Studies}

In Table 1 we have summarized the 5 papers comparing multilevel CDA with ACDF. Kim et al. performed a prospective cohort study of 105 patients with symptomatic single- or 2-level CDD treated with the Bryan Cervical Artificial Disc Prosthesis (Medtronic Sofamor Danek). The clinical results were compared with a control group of patients who underwent ACDF. ${ }^{12}$ Outcome measurements included the visual analog scale (VAS) for pain and the Neck Disability Index (NDI), whereas radiological evaluation included assessment of cervical ROM, functional spinal unit, overall sagittal alignment (C2-7), anterior intervertebral height, posterior intervertebral height, and 
TABLE 1. Summary of the 5 studies comparing multilevel CDA versus ACDF

\begin{tabular}{|c|c|c|c|c|c|}
\hline $\begin{array}{l}\text { Authors } \\
\text { \& Year }\end{array}$ & $\begin{array}{l}\text { Study } \\
\text { Design }\end{array}$ & $\begin{array}{l}\text { Population } \\
\text { \& Inclusion } \\
\text { Criteria }\end{array}$ & Intervention & Follow-Up & $\begin{array}{l}\text { Conclusions } \\
\quad \& \text { LOE }\end{array}$ \\
\hline $\begin{array}{c}\text { Kim et al., } \\
2009^{12}\end{array}$ & $\begin{array}{l}\text { Prospective } \\
\text { cohort } \\
\text { study }\end{array}$ & $\begin{array}{l}105 \text { pts w/ } \\
\text { symp- } \\
\text { tomatic } \\
\text { single- or } \\
\text { 2-level } \\
\text { CDD }\end{array}$ & $\begin{array}{l}54 \text { pts underwent } \\
\text { ACDF ( } 26 \text { single } \\
\& 28 \text { 2-level), } 51 \\
\text { pts underwent } \\
\text { CDA ( } 39 \text { single- } \\
\& 12 \text { 2-level) }\end{array}$ & $\begin{array}{l}\text { Mean } 19 \text { mos (range } \\
12-38 \text { mos), CDA } \\
\text { group; mean } \\
20 \text { mos (range } \\
12-40 \text { mos), } \\
\text { ACDF group }\end{array}$ & $\begin{array}{l}\text { VAS \& NDI scores showed no significant improvement from } \\
\text { preop compared to last follow-up. Radiological changes after } \\
\text { op were } 3.5 \text { times more prevalent in ACDF group. ROM was } \\
\text { preserved in CDA vs ACDF. LOE: II. }\end{array}$ \\
\hline $\begin{array}{c}\text { Fay et al., } \\
2014\end{array}$ & $\begin{array}{l}\text { Retrospec- } \\
\text { tive } \\
\text { study }\end{array}$ & $\begin{array}{l}77 \text { pts } \\
\text { consecu- } \\
\text { tively } \\
\text { treated } \\
\text { for } \\
\text { 2-level } \\
\text { CDD }\end{array}$ & $\begin{array}{l}37 \text { pts underwent } \\
\text { CDA (Bryan } \\
\text { artificial disc), } 40 \\
\text { pts underwent } \\
\text { ACDF }\end{array}$ & $\begin{array}{l}\text { Mean } 39.6 \pm 6.7 \\
\quad \text { mos }\end{array}$ & $\begin{array}{l}\text { Estimated blood loss was similar in both groups ( } p=0.135) \text {. A } \\
\text { longer op time was reported for the arthroplasty group ( } 315.5 \\
\pm 82.0 \text { mins vs } 224.9 \pm 61.8 \text { mins, } p<0.001) \text {. Clinical outcome } \\
\text { improved significantly in both groups (VAS, JOA scores, \& } \\
\text { NDI) w/o differences in adverse effects. ROM improved in the } \\
\text { CDA group after surgery when compared w/ preop findings } \\
\left(23.5^{\circ} \text { vs } 20.1^{\circ}, p=0.018\right) \text {. LOE: III. }\end{array}$ \\
\hline $\begin{array}{l}\text { Cheng } \\
\text { et al., } \\
2009\end{array}$ & $\begin{array}{l}\text { Prospective } \\
\text { random- } \\
\text { ized }\end{array}$ & $\begin{array}{c}65 \text { pts w/ } \\
\text { CDD }\end{array}$ & $\begin{array}{l}31 \text { pts underwent } \\
\text { 2- level CDA, } 34 \\
\text { pts underwent } \\
\text { ACDF }\end{array}$ & Minimum 24 mos & $\begin{array}{l}\text { Clinical outcomes (NDI \& VAS) improved in both groups ( } p< \\
0.001) \text {. Arm pain after at } 2 \text { yrs of follow-up; } 2.7 \text { (ACDF group) } \\
\text { vs 1.4 (CDA group) ( } p=0.013 \text { ). NDI was also statistically better } \\
\text { in the CDA group (11) after } 2 \text { yrs vs the ACDF group (19) ( } p= \\
\text { 0.023). Radiological assessment revealed no subsidence in } \\
\text { the CDA group \& a mean } 7.9^{\circ} \text { of flexion-extension at the index } \\
\text { level that was maintained after } 2 \text { yrs compared w/ a mean } 0.5^{\circ} \\
\text { of motion in the fusion level. LOE: II. }\end{array}$ \\
\hline $\begin{array}{l}\text { Davis } \\
\text { et al. } \\
2015\end{array}$ & $\begin{array}{l}\text { Prospective } \\
\text { random- } \\
\text { ized }\end{array}$ & $\begin{array}{c}330 \text { pts w/ } \\
\text { CDD }\end{array}$ & $\begin{array}{l}225 \text { pts in the CDA } \\
\text { group, } 105 \text { pts in } \\
\text { the ACDF group }\end{array}$ & Minimum 48 mos & $\begin{array}{l}\text { Both groups had significant clinical improvement, but CDA pts } \\
\text { had greater improvement for some outcome measurements } \\
\text { (NDI scores, SF-12 PCS scores, pt satisfaction, \& also for } \\
\text { overall success). There were no statistical differences for } \\
\text { major complications. ACDF pts had more reops at the index } \\
\text { level ( } p<0.001) \text {. Pts w/ CDA maintained their ROM compared } \\
\text { w/ preop whereas pts who underwent ACDF did not. LOE: I. }\end{array}$ \\
\hline $\begin{array}{l}\text { Radcliff } \\
\text { et al., } \\
2016\end{array}$ & $\begin{array}{l}\text { Prospective } \\
\text { random- } \\
\text { ized }\end{array}$ & $\begin{array}{c}225 \text { pts w/ } \\
\text { CDD }\end{array}$ & $\begin{array}{c}186 \text { pts w/ CDA } \\
72 \text { pts w/ ACDF } \\
\text { (after } 60 \text { mos) }\end{array}$ & Minimum 60 mos & $\begin{array}{l}\text { Both groups had significant improvements in all outcome scores, } \\
\text { but CDA pts had more improvement compared to ACDF when } \\
\text { considering the NDI, SF-12 PCS, \& overall satisfaction. A high- } \\
\text { er reop rate in the ACDF group vs CDA group ( } p=0.003 \text { ) was } \\
\text { reported. CDA had less CASP }(50.7 \%) \text { compared to pts who } \\
\text { underwent ACDF }(90.5 \%)(p<0.001) \text {. ROM was preserved in } \\
\text { the arthroplasty group, despite a } 29.7 \% \text { rate of HO. LOE: I. }\end{array}$ \\
\hline
\end{tabular}

$\mathrm{LOE}=$ level of evidence; $p t s=$ patients

radiographic changes at the implanted and adjacent levels with dynamic cervical spine radiographs and MRI.

A total of 105 patients were included, 54 of whom underwent an ACDF (26 single-level and 28 two-level) and 51 of whom underwent CDA (39 single-level and 12 twolevel). The mean follow-up was 19 months (range 12-38 months) for CDA and 20 months (range 12-40 months) for the ACDF group. Based on VAS and NDI findings, there was clinical improvement from preoperative scores compared with the last follow-up, but it was not significant between the 2 groups for single-level (VAS $\mathrm{p}=0.8371$, NDI $p=0.2872$ ) and for 2-level (VAS $p=0.2938$, NDI $p$ $=0.6753$ ) surgeries.

Based on radiological outcomes, there were significant changes in cervical ROM for 1 or 2-level CDA versus ACDF, except at the upper adjacent segment for singlelevel operations $(p=0.2872)$. These investigators also reported that radiological changes after surgery were 3.5 times more prevalent in the ACDF group. They concluded that the clinical status improved similarly in both groups for 1- and 2-level anterior cervical procedures, with some potential benefits of CDA in preserving motion, which may result in less CASP with a longer follow-up.

Fay et al. performed a retrospective study of 77 patients consecutively treated for 2-level CDD. ${ }^{8}$ A total of 37 patients underwent CDA (using the Bryan artificial disc) and 40 patients underwent an ACDF. Clinical outcomes were assessed using the VAS for neck and arm pain, the Japanese Orthopaedic Association (JOA) score, and the NDI. All patients underwent radiological assessment for fusion and heterotopic ossification (HO) with plain radiographs and CT scans. The investigators reported that the arthroplasty group had a significantly younger mean age $(52.1 \pm 9.1$ years) than the ACDF group $(63.0 \pm 10.6$ years, $\mathrm{p}<0.001)$. The mean follow-up was $39.6 \pm 6.7$ months. Considering surgical data, the estimated blood loss was 
similar in both groups $(\mathrm{p}=0.135)$, but a longer operation time was reported for the arthroplasty group $(315.5 \pm 82.0$ vs $224.9 \pm 61.8$ minutes, $\mathrm{p}<0.001)$. The clinical outcome improved significantly in both groups (VAS, JOA score, and NDI) without differences in adverse effects. However, ROM improved in the CDA group after surgery when compared with preoperative findings $\left(23.5^{\circ}\right.$ vs $20.1^{\circ}, \mathrm{p}=$ 0.018). The authors concluded that CDA was as effective and safe as ACDF for 2-level cervical disc diseases, and that it has the potential advantage of motion preservation.

Cheng et al. performed a prospective and randomized study including 65 patients with CDD (radiculopathy and myelopathy), comparing 2 groups: 31 patients who underwent a 2-level CDA (Bryan Cervical Artificial Disc-arthroplasty group) and 34 patients who underwent a 2-level ACDF with autologous graft and plate (ACDF group). ${ }^{4}$ Clinical outcome was assessed using the VAS, NDI, and the 36-Item Short Form Health Survey (SF-36) during a minimum follow-up of 2 years. Radiological evaluation was performed by an independent radiologist who assessed for subsidence of the prosthesis, ROM, and stability. Preoperative symptoms were similar between both groups $(p=0.10)$, as were demographic characteristics $(p>0.05)$. Three patients were lost to follow-up.

Considering clinical outcomes, NDI and VAS scores improved after 2 years in both groups $(\mathrm{p}<0.001)$. Neck pain (assessed with the VAS) before surgery was 7.1 (ACDF group) and 7.3 (CDA group); after 2 years of follow-up, the VAS was 2.6 (ACDF group) versus 1.5 (CDA group) (p $=0.012$ ). Arm pain (also assessed with the VAS) before surgery was 7.2 (ACDF group) and 7.1 (CDA group); after at 2 years of follow-up it was 2.7 (ACDF group) versus 1.4 (CDA group) $(\mathrm{p}=0.013)$. The NDI was also statistically better in the CDA group (11) after 2 years versus the ACDF group (19) $(p=0.023)$.

Radiological assessment revealed no subsidence in the CDA group and a mean $7.9^{\circ}$ of flexion-extension at the index level that was maintained after 2 years (no statistical difference from preoperative measurement; $p=0.35$ ) compared with a mean $0.5^{\circ}$ of motion in the fusion level, which was statistically different from preoperative assessment of cervical ROM ( $p<0.001)$.

These authors concluded that 2-level CDA was safe and even potentially better than ACDF considering the findings of some clinical outcome assessment tools and based on ROM preservation.

Davis et al. reported the results of a prospective randomized study evaluating the safety and effectiveness of 2-level CDA using a Mobi-C artificial disc compared with ACDF after a minimum 48 months of follow-up? ${ }^{7}$ A total of 330 patients with CDD were randomized, 225 patients in the CDA group and 105 patients in the ACDF group, in 24 US centers. Outcome was assessed using the NDI, the VAS for arm and neck pain, the 12-Item Short Form Health Survey (SF-12), subsequent surgical intervention, complications, neurological function, return to work, ROM, complications, patient satisfaction, and adjacentlevel degeneration. After 48 months, the follow-up rate was $89 \%$ in the CDA group and $81.2 \%$ in the ACDF group. Clinical and demographic characteristics at baseline were similar, without statistical differences.
These investigators reported that both groups had significant clinical improvement, but the patients treated with CDA had greater improvement for some outcome measurements (NDI scores, SF-12 Physical Component Summary [PCS] scores, patient satisfaction, and also for overall success). There were no statistical differences for major complications (4\% in the CDA group vs $7.6 \%$ in the ACDF group) but patients treated with ACDF had more reoperations at the index level $(15.2 \%$; 16 of 105 patients, with a total of 18 surgeries) compared with patients who underwent CDA (4\%; 9 of 225 patients) ( $p<0.001)$.

Symptomatic pseudarthrosis was the most common cause of reoperation in the ACDF group, and reoperations in the CDA group included those due to stenosis, device migration, persistent pain, and poor endplate fixation. Patients with CDA maintained their ROM compared with preoperative findings, in contrast to patients who underwent ACDF. Fusion was not achieved in $14.8 \%$ of the patients after 48 months. Clinically relevant $\mathrm{HO}$ was present in $25.6 \%$ of the CDA group.

Davis et al. concluded that CDA was safer and even slightly more effective than ACDF for treatment of 2-level CDD after 48 months of follow-up, and that CDA preserved cervical ROM.

Finally, Radcliff et al. performed an independent critical review of the data published by Davis et al. (primarily sponsored by the device manufacturer) comparing the Mobi-C disc with ACDF, but now after a longer follow-up of 60 months. ${ }^{17}$ The methodology of the study was already described above. Three independent authors without affiliation with the investigational device exemption study or financial bias toward the study sponsor critically reviewed the data and the methodology. The follow-up rates after 60 months in the 225 patients who received the Mobi-C cervical arthroplasty versus the 105 patients who underwent an ACDF were $90.7 \%$ and $86.7 \%$, respectively $(\mathrm{p}=0.39)$. Although both groups had significant improvements in all outcome scores, CDA patients had more improvement compared with ACDF when considering the NDI, SF-12 PCS, and overall satisfaction. These authors also reported a higher reoperation rate in the ACDF group (16\%), versus $4 \%$ in the CDA group ( $\mathrm{p}=0.003)$, without differences in the adverse events rates. Additionally, similarly to the 4-year follow-up study, patients in the CDA group had less CASP $(50.7 \%)$ compared with patients who underwent ACDF $(90.5 \%)$ ( $\mathrm{p}<0.001)$. The ROM was preserved in the arthroplasty group, despite a $29.7 \%$ rate of HO. These results were similar to those reported by Davis et al. ${ }^{7}$

\section{Single-Level CDA Versus Multilevel CDA-8 Studies}

In Table 2 we have summarized the 8 papers comparing single-level CDA versus multilevel CDA. Pimenta et al. reported the results of a prospective case series of 229 CDAs performed in 140 patients to treat symptomatic CDD (radiculopathy and/or myelopathy) using a porous material-coated motion device. ${ }^{16} \mathrm{~A}$ total of 71 patients underwent 1-level arthroplasty, and their outcome was compared with that in 69 patients who underwent multilevel cervical arthroplasty (53 patients with 2, 12 with 3 , and 4 with 4 levels). Indications for CDA included patients with cervical kyphosis, previous anterior cervical surgery, and 
TABLE 2. Summary of the 8 studies comparing single-level versus multilevel CDA

\begin{tabular}{|c|c|c|c|c|c|}
\hline $\begin{array}{l}\text { Authors } \\
\& \text { Year }\end{array}$ & $\begin{array}{l}\text { Study } \\
\text { Design }\end{array}$ & $\begin{array}{l}\text { Population } \\
\text { \& Inclusion } \\
\text { Criteria }\end{array}$ & Intervention & Follow-Up & $\begin{array}{l}\text { Conclusions } \\
\quad \& \text { LOE }\end{array}$ \\
\hline $\begin{array}{l}\text { Pimenta } \\
\text { et al., } \\
2007\end{array}$ & $\begin{array}{l}\text { Prospec- } \\
\text { tive case } \\
\text { series }\end{array}$ & $\begin{array}{l}140 \text { pts w/ } \\
\text { CDD }\end{array}$ & $\begin{array}{l}71 \text { pts underwent } 1 \text {-level } \\
\text { CDA, } 69 \text { pts underwent } \\
\text { multilevel CDA ( } 53 \text { pts } \\
\text { had } 2 \text { levels, } 12 \text { had } 3 \\
\text { \& } 4 \text { had } 4 \text { levels) }\end{array}$ & $\begin{array}{l}\text { Mean } 26.8 \\
\quad \text { mos (range } \\
12-42 \text { mos) }\end{array}$ & $\begin{array}{l}\text { Mean improvement of the NDI for multilevel surgery was } 52.6 \% \text {, } \\
\text { compared w/ } 37.6 \% \text { for single level }(p<0.001) \text {. Mean improve- } \\
\text { ment in VAS score for multilevel cases was } 65.9 \% \text {, vs } 58.4 \% \\
\text { for single level. Reop rates were similar in single-level ( } 3 \\
\text { cases) \& multilevel ( } 2 \text { cases) pts. LOE: II. }\end{array}$ \\
\hline $\begin{array}{l}\text { Kim et al. } \\
200911\end{array}$ & $\begin{array}{l}\text { Retrospec- } \\
\text { tive } \\
\text { study }\end{array}$ & $\begin{array}{l}52 \text { pts w/ } \\
\text { CDD }\end{array}$ & $\begin{array}{l}52 \text { pts had CDA \& } 16 \text { un- } \\
\text { derwent multilevel CDA } \\
\text { (13 pts had } 2 \text { levels \& } 3 \\
\text { had } 3 \text { levels) }\end{array}$ & $\begin{array}{l}\text { Mean } 29.2 \\
\text { mos (range } \\
6-36)\end{array}$ & $\begin{array}{l}\text { All pts were satisfied w/ the surgical results according to Odom's } \\
\text { criteria, w/ a significant improvement in VAS \& NDI ( } p<0.05 \text { ) } \\
\text { findings. CDA was able to maintain ROM similar to the preop } \\
\text { state at the treated level, \& cervical lordosis was maintained in } \\
97 \% \text { of pts w/ preop lordosis. Lordosis was reported in } 70 \% \text { of } \\
\text { the pts who had preop kyphosis. LOE: III. }\end{array}$ \\
\hline $\begin{array}{l}\text { Wu et al., } \\
2012\end{array}$ & $\begin{array}{l}\text { Retrospec- } \\
\text { tive } \\
\text { cohort } \\
\text { study }\end{array}$ & $\begin{array}{l}86 \text { pts w/ } \\
\text { CDD }\end{array}$ & $\begin{array}{l}36 \text { underwent } 1 \text {-level } \\
\text { CDA \& } 50 \text { underwent } \\
\text { multilevel CDA }\end{array}$ & $\begin{array}{l}\text { Minimum } 24 \\
\text { mos }\end{array}$ & $\begin{array}{l}\text { Clinical outcomes improved significantly in both groups w/o } \\
\text { significant differences at } 12 \text { \& } 24 \text { mos. A higher HO rate was } \\
\text { observed in pts w/ multilevel ops compared to those who had } \\
\text { single-level surgery (66\% vs } 25 \% \text {, respectively; } p<0.001 \text { ), but } \\
97.7 \% \text { of the levels remained mobile, despite the HO. Mobility } \\
\text { of CDA in the single-level group was } 100 \% \text {, vs } 96 \% \text { in the multi- } \\
\text { level group, questioning the clinical significance of HO. LOE: III. }\end{array}$ \\
\hline $\begin{array}{l}\text { Cardoso } \\
\quad \& \text { Ros- } \\
\text { ner, } \\
2010\end{array}$ & $\begin{array}{l}\text { Retrospec- } \\
\quad \text { tive } \\
\text { review }\end{array}$ & $\begin{array}{l}10 \text { pts w/ } \\
\text { CDD }\end{array}$ & $\begin{array}{l}10 \text { pts underwent multi- } \\
\text { level CDA ( } 3 \text { pts had } \\
\text { previous ACDF at other } \\
\text { levels) }\end{array}$ & Mean & $\begin{array}{l}\text { The authors did not report clinical outcomes. However, they re- } \\
\text { ported that there were no cases of implant failure or kyphosis } \\
\text { or HO. LOE: III. }\end{array}$ \\
\hline $\begin{array}{l}\text { Bae et al., } \\
\quad 2015\end{array}$ & $\begin{array}{l}\text { Prospective } \\
\text { random- } \\
\text { ized }\end{array}$ & $\begin{array}{l}389 \text { pts w/ } \\
\text { CDD }\end{array}$ & $\begin{array}{l}164 \text { pts underwent single- } \\
\text { level CDA, } 225 \text { pts had } \\
\text { 2-level CDA }\end{array}$ & $\begin{array}{l}\text { Minimum } 48 \\
\text { mos }\end{array}$ & $\begin{array}{l}\text { Clinical outcome measures were statistically similar btwn the } 2 \\
\text { groups, as well as reop rates \& major complications. Cervical } \\
\text { ROM was maintained in both groups similarly. LOE: I. }\end{array}$ \\
\hline $\begin{array}{l}\text { Huppert } \\
\text { et al., } \\
2011\end{array}$ & $\begin{array}{l}\text { Prospective } \\
\text { study }\end{array}$ & $\begin{array}{l}231 \text { pts w/ } \\
\text { CDD }\end{array}$ & $\begin{array}{l}175 \text { had single-level CDA, } \\
56 \text { had } 2-4 \text { levels ( } 118 \\
\text { CDA) }\end{array}$ & $\begin{array}{l}\text { Minimum } 24 \\
\text { mos }\end{array}$ & $\begin{array}{l}\text { The mean NDI \& VAS scores (for neck \& arm pain) improved in } \\
\text { both groups similarly }(p>0.05) \text {. Reops \& complications were } \\
\text { similar in both groups }(p=0.109) \text {, except for dysphagia \& } \\
\text { dysphonia, which were more prevalent in the multilevel group } \\
(p=0.0024) \text {. Subjective satisfaction was similar in both groups } \\
(>94 \%) \text {. There was more HO in the single-level group than in } \\
\text { the multilevel ( } p=0.0233) \text {. The mean ROM was preserved or } \\
\text { even improved after CDA in both groups. LOE: II. }\end{array}$ \\
\hline $\begin{array}{l}\text { Goffin } \\
\text { et al., } \\
2010\end{array}$ & $\begin{array}{l}\text { Prospective } \\
\text { study }\end{array}$ & $98 \mathrm{pts}$ & $\begin{array}{l}89 \text { had single-level CDA \& } \\
9 \text { had 2-level CDA }\end{array}$ & $\begin{array}{l}\text { 4- \& 6-yr } \\
\text { results }\end{array}$ & $\begin{array}{l}\text { 2-level CDA had a longer mean op time than the single level. } \\
\text { There were similar neurological success rates, w/ some drop } \\
\text { for both at } 4 \text { yrs' follow-up. There was preservation of motion } \\
\text { at the index level for both } 1 \text { - \& 2-level CDA. LOE: II. }\end{array}$ \\
\hline $\begin{array}{l}\text { Tu et. al, } \\
2011\end{array}$ & $\begin{array}{l}\text { Retrospec- } \\
\text { tive } \\
\text { study }\end{array}$ & $\begin{array}{l}36 \text { pts w/ } \\
\text { CDD }\end{array}$ & $\begin{array}{l}20 \text { pts had single-level } \\
\text { CDA \& } 16 \text { pts had } 2 \\
\text { levels }\end{array}$ & $\begin{array}{l}\text { Mean } \\
19.03 \pm 4.64 \\
\text { mos }\end{array}$ & $\begin{array}{l}\text { HO was identified in } 18(50 \%) \text { of } 36 \text { pts. } 19 \text { of } 25(76 \%) \text { were in } \\
\text { pts who had undergone 2-level CDAs. Although there was a } \\
\text { higher prevalence of HO, } 96.2 \% \text { of the treated levels ( } 50 \text { of } 52) \\
\text { had some segmental ROM on dynamic radiographs \& HO did } \\
\text { not affect the final clinical outcome, as there was no correla- } \\
\text { tion between VAS \& HO. LOE: III. }\end{array}$ \\
\hline
\end{tabular}

CASP. The mean follow-up was 26.8 months (range 12-42 months) in the single-level group versus 26.6 months (range 12-42 months) in the multilevel group, without statistical differences in baseline demographics. Outcome was assessed with the Odom Outcome Classification, NDI, and VAS. The investigators reported that patients with multilevel surgeries had greater clinical improvement than those who had only single-level disease. The mean improvement of the NDI for multilevel surgery was $52.6 \%$, compared with $37.6 \%$ for single level ( $p<0.001)$. The mean improve- ment in the VAS score for multilevel cases was $65.9 \%$, versus $58.4 \%$ for single level. The reoperation rates were similar in patients with single-level ( 3 cases) and multilevel (2 cases) disease. The authors concluded that multilevel CDA was safe and that it also results in improvement of clinical outcome for patients with multilevel CDD.

Kim et al. retrospectively reviewed the results in patients who underwent surgery using the Bryan cervical artificial disc (52 patients, of whom 16 underwent multilevel surgery; 13 patients had 2 levels and 3 patients had 
3 levels). ${ }^{11}$ Clinical assessment was performed using the VAS, the Odom Outcome Classification, and the NDI. Radiological outcome was evaluated using dynamic radiographs to measure cervical ROM, C2-7 Cobb angle, and the angle of the functional spine unit. After a mean followup of 29.2 months (range 6-36 months), the investigators reported that all patients were satisfied with the surgical results according to Odom's criteria, with a significant improvement in VAS and NDI findings $(\mathrm{p}<0.05)$. Cervical disc arthroplasty was able to maintain ROM similar to the preoperative state at the treated level, and cervical lordosis was maintained in $97 \%$ of patients with preoperative lordosis. Lordosis was reported in $70 \%$ of the patients who had preoperative kyphosis. The authors concluded that CDA was safe and effective for both single-level and multilevel CDD, preserving ROM.

Wu et al. performed a retrospective clinical study of patients who underwent single- and multilevel CDA to evaluate potential differences between these groups. ${ }^{24}$ Of a total of 102 patients, only those with a minimum 24 months of follow-up were included; a total of 86 patients (84.3\%) met that criterion. Clinical outcome was assessed using the VAS for neck and arm pain as well as NDI, and radiological assessment was performed with dynamic radiographs and CT scans.

Although patients who had multilevel surgeries were older $(51.3 \pm 8.6$ years vs $46.3 \pm 11.2$ years in the singlelevel group; $p=0.02$ ), there were no other demographic differences between the 2 groups. Clinical outcomes improved significantly in both groups, without significant differences at 12 and 24 months.

A higher HO rate was observed in multilevel patients compared with those who had single-level surgery $(66 \%$ vs $25 \%$, respectively; $p<0.001$ ), but $97.7 \%$ of the levels remained mobile, despite the HO. The mobility of Bryan discs in the single-level group was $100 \%$ versus $96 \%$ in the multilevel group, questioning the clinical significance of $\mathrm{HO}$. The investigators concluded that multilevel surgery was as safe and effective as single level, but the impact of $\mathrm{HO}$ in the long term requires further investigation.

Cardoso and Rosner described the results in 10 patients who had 2-level surgery for CDD using Prestige-ST. ${ }^{3}$ The mean follow-up was 12 months. Three patients had previous ACDF at other levels. The investigators did not report clinical outcome measurements, but there were no cases of implant migration, kyphosis, or HO in this series. They concluded that 2-level CDA was safe to treat multilevel CDD.

Bae et al. performed a prospective, randomized, controlled, multicenter study to investigate the clinical outcomes of 1- and 2-level CDA. ${ }^{2}$ A total of 164 patients underwent single-level, versus 225 patients who had 2-level CDA. A minimum 48-month follow-up was required. The investigators compared the outcomes of 1- versus 2-level surgery using NDI, VAS for neck and arm pain, SF12 Mental Component Summary (MCS)/PCS, cervical ROM, complication rates, and reoperation rates.

The follow-up rate after 48 months was $83.1 \%$ (single level) versus $89 \%$ ( 2 levels). The clinical outcome measures were statistically similar between the 2 groups. There was only 1 case of CDA migration, in a 2-level group. Reoperation rates (3\% single-level vs $4 \%$ in 2 levels) and major complications ( $4.3 \%$ single-level vs $4 \%$ in 2 levels) were similar. Cervical ROM was maintained in both groups similarly. The investigators concluded that 2-level surgery was as effective as single level.

Huppert et al. prospectively evaluated a total of $231 \mathrm{pa}-$ tients with CDD treated with CDA..$^{10}$ Their objective was to compare the results of single- versus multilevel surgery. After a minimum follow-up of 24 months, 175 patients had 1 level treated and 56 had 2 or more levels (2-4 levels, 118 devices). Clinical outcome was compared using NDI, VAS, and patient satisfaction. Radiological outcome was assessed using dynamic lateral cervical radiographs to measure ROM and HO. The investigators reported that the mean NDI and VAS scores (for neck and arm pain) improved in both groups similarly ( $p>0.05$ ). In both groups, the rate of return to work at 2 years increased significantly ( $p<0.0001)$, without differences between the groups ( $p$ $=0.0985$ ), although there was a trend to the patients with single-level operations returning earlier (4.8 months vs 7.5 months; $p=0.0079$ ).

Reoperations and complications were similar in both groups $(p=0.109)$, except for dysphagia and dysphonia, which were more prevalent in the multilevel group (9 of 56 cases [16\%] vs 6 of 175 cases [3.4\%]; $p=0.0024$ ), but they all resolved during the follow-up period. Subjective satisfaction was similar in both groups (> 94\%).

There was more HO in the single-level than in the multilevel group $(p=0.0233)$. The mean ROM was preserved or even improved after CDA in both groups; the mean ROM increased from $7.2^{\circ}$ to $9.5^{\circ}$ in the single-level and from $6.1^{\circ}$ to $7.9^{\circ}$ in the multilevel group after 24 months ( $p=$ 0.0002 ). Huppert et al. concluded that multilevel CDA was feasible, safe, and effective for treating multilevel CDD.

Goffin et al. reported the results of a prospective study of 98 patients; 89 had a single-level CDA and 9 had a 2-level surgery. ${ }^{9}$ Patients had cervical radiculopathy (> $90 \%$ ) or myelopathy secondary to CDD. The study used the Bryan artificial disc and was sponsored by the device manufacturer. Clinical outcome was assessed using the SF-36, NDI, VAS for neck and arm pain, Odom classification, and neurological outcomes. Radiological outcome was assessed using dynamic cervical lateral radiographs.

The 2-level CDA had a longer mean operative time than the single-level treatment, as expected. Demographic characteristics between patients with the single- and 2-level surgeries were similar, except that the patients with 2-level operations were 6 years older than those with the single levels. The investigators reported similar neurological success rates, with some drop for both at 4 years of follow-up. Considering radiological outcomes, there was preservation of motion at the index level. For patients with 1-level operations, after 4 and 6 years, the mean angular motion was $7.3^{\circ}$ and $7.7^{\circ}$, respectively. For patients with 2-level operations, the mean angular motion at the caudal level was $5.7^{\circ}$ and $6.0^{\circ}$, and cephalad values were $4.2^{\circ}$ and $6.2^{\circ}$, respectively, after 4 and 6 years.

Considering adverse events, 2 patients had surgery-related events: one had device migration and another had extrusion of the drainage catheter and a prevertebral hematoma requiring surgical evacuation. One patient had hoarseness and dysphonia after an additional procedure was performed 
TABLE 3. Summary of a study discussing the role of multilevel CDA after a previous cervical spine surgery

\begin{tabular}{|c|c|c|c|c|c|}
\hline $\begin{array}{l}\text { Authors } \\
\& \text { Year }\end{array}$ & $\begin{array}{l}\text { Study } \\
\text { Design }\end{array}$ & $\begin{array}{l}\text { Population } \\
\text { \& Inclusion } \\
\text { Criteria }\end{array}$ & Intervention & Follow-Up & $\begin{array}{l}\text { Conclusions } \\
\quad \& \text { LOE }\end{array}$ \\
\hline $\begin{array}{c}\text { Sekhon } \\
\text { et al., } \\
2005\end{array}$ & $\begin{array}{l}\text { Prospective } \\
\text { study }\end{array}$ & $\begin{array}{c}15 \text { pts w/ } \\
\text { CDD }\end{array}$ & $\begin{array}{l}24 \text { CDAs were performed } \\
\text { (16 had } 1 \text { level, } 7 \text { had } 2 \\
\text { levels, \& } 1 \text { had } 3 \text { levels). } \\
6 \text { pts had a previous } \\
\text { posterior foraminotomy, \& } \\
9 \text { had a previous ACDF. }\end{array}$ & $\begin{array}{l}\text { 12-43 mos } \\
\text { (mean } \\
24 \pm 10.5 \\
\text { mos) }\end{array}$ & $\begin{array}{l}\text { Good clinical outcomes were obtained in all cases (the mean VAS } \\
\text { score was } 7.8 \pm 3.3 \text { preop \& } 1.4 \pm 2.6 \text { at the last follow-up, \& the } \\
\text { mean ODI was } 27.16 \pm 15.6 \text { preop \& } 17.6 \pm 8.5 \text { after surgery). } \\
\text { One pt, who had been treated at a level adjacent to a previous } \\
\text { 2-level fusion, developed hypermobility w/ internal migration of } \\
\text { the device, but no revision surgery was performed. LOE: II. }\end{array}$ \\
\hline
\end{tabular}

with another CDA to treat an adjacent-segment problem 15 months after the first surgery. Most of the adverse events were not related to the Bryan device itself. In 1 patient the Bryan disc was removed and the segment was fused after 6 years, due to recurrent posterior osteophyte formation. Three patients underwent a posterior decompression for radiculopathy and/or myelopathy. Four patients had surgery at other cervical levels, 3 of them with a new CDA.

$\mathrm{Tu}$ et al. retrospectively reviewed the data in patients who had CDAs with the Bryan disc for 1- or 2-level CDD and who were followed for at least 12 months. ${ }^{23}$ The investigators specifically evaluated the role of $\mathrm{HO}$ and its effect on outcome, using plain radiographs and CT scans. Clinical follow-up was assessed using the VAS for neck and arm pain and Odom's outcome classification. From an initial series of 46 patients, 36 had adequate follow-up and complete radiological data. Twenty patients $(55.6 \%)$ had single-level surgery and $16(44.4 \%)$ had 2-level CDA (52 levels in total). The mean radiological follow-up was 19.03 \pm 4.64 months. Heterotopic ossification was identified in $18(50 \%)$ of 36 patients and in $25(48.1 \%)$ of 52 treated levels. Nineteen of those 25 levels $(76 \%)$ were in patients who had undergone 2-level CDAs. These authors also reported a tendency for $\mathrm{HO}$ development among older patients, but this finding was not statistically significant (mean $48.8 \pm$ 6.8 years in patients with $\mathrm{HO}$ vs $44.4 \pm 7.2$ in those without $\mathrm{HO}, \mathrm{p}=0.065)$. Although there was a higher prevalence of $\mathrm{HO}, 96.2 \%$ of the treated levels (50 of 52) had some segmental ROM on dynamic radiographs and $\mathrm{HO}$ did not affect the final clinical outcome; there was no correlation between VAS and HO. Finally, the concordance of grading $\mathrm{HO}$ with radiographs and $\mathrm{CT}$ was high.

\section{Multilevel CDA After a Previous Cervical Spine Surgery-1 Study}

In Table 3 we summarized the study of Sekhon et al., discussing the role of multilevel CDA after a previous cervical spine surgery. Sekhon et al. evaluated CDA in patients who had undergone a previous cervical surgery. ${ }^{22}$ These authors performed a prospective study involving nonrandomized patients who had a previous cervical spine surgery (a posterior cervical foraminotomy or an ACDF) and who had new or persistent symptoms secondary to CDD.

A total of 24 CDAs were performed in 15 patients during a 30-month period. Sixteen patients $(66.7 \%)$ had a 1-level CDA, 7 had 2 levels (29.2\%), and 1 had 3 levels (4.2\%). Six patients $(40 \%)$ had a previous posterior foraminotomy and $9(60 \%)$ had an $\mathrm{ACDF}$ prior to the CDA.
Clinical outcome was assessed using the VAS for neck and arm pain, and the Oswestry Disability Index (ODI). Radiological assessment was performed by an independent radiologist using dynamic cervical radiographs and CT scans. Follow-up ranged from 12 to 43 months (mean of 24.2 months). Good clinical outcomes were obtained in all cases (the mean VAS score was $7.8 \pm 3.3$ preoperatively and $1.4 \pm 2.6$ at the last follow-up, and the mean ODI score was $27.16 \pm 15.6$ preoperatively and $17.6 \pm 8.5$ after surgery). One patient, who had been treated at a level adjacent to a previous 2-level fusion, developed hypermobility with internal migration of the device, but no revision surgery was performed.

The authors concluded that CDA may be performed in single-level or multilevel CDD even after a previous cervical spine surgery. However, they suggest that preoperative hypermobility should be treated with caution.

\section{Discussion}

The majority of the studies suggest that multilevel CDA appears to be a good alternative to ACDF at up to 5 years postoperatively., $, 8,10,12,17$ However, some caution is necessary to interpret our compiled data: besides the potential sponsorship of industry interested in a new device, the inclusion and exclusion criteria of the majority of the studies must be considered. These include preserved disc height (at least $3 \mathrm{~mm}$ ), good bone density (T-score $>1.5$ ), no marked instability, and no severe facet joint degeneration, among many others.1,13,16,22,23 The good results with CDAs for multilevel CDD may increase their usage, but the limited indications for arthroplasty must be carefully adhered to. Although multilevel CDA is a new tool for the surgeons' armamentarium to treat $\mathrm{CDD}$, ACDF remains the procedure of choice for patients with severe disc collapse and cervical deformities, as well as for those with osteoporosis or for older patients with severe degenerative changes.

Multilevel anterior cervical surgery is associated with higher local complication rates, such as dysphagia and dysphonia, when compared with single-level surgeries. ${ }^{10,20,21}$ These higher local complications are related to surgical exposure and may not result in an advantage of CDA over ACDF. A major concern about multilevel CDA was HO. ${ }^{18,23}$ Risk factors such as diffuse idiopathic skeletal hyperostosis, ankylosing spondylitis, and male sex were described in the orthopedic literature. ${ }^{15,18}$ Although multilevel surgery may be associated with an increased $\mathrm{HO}$ rate, this did not appear to affect patients' outcome or ROM 
during the various studies' follow-up period. ${ }^{24,25}$ Certainly, the long-term impact of $\mathrm{HO}$ may be a greater limitation in ROM, but even a limited period with motion preservation may be preferable to an ACDF.

\section{Conclusions}

Our literature review supports the use of multilevel CDA for treating CDD in carefully selected patients. Surgeons must be aware of the best indications for CDA as an alternative to ACDF. Longer-term follow-up is necessary to prove the ultimate superiority of CDA surgery over ACDF.

\section{References}

1. Alvin MD, Mroz TE: The Mobi-C cervical disc for one-level and two-level cervical disc replacement: a review of the literature. Med Devices (Auckl) 7:397-403, 2014

2. Bae HW, Kim KD, Nunley PD, Jackson RJ, Hisey MS, Davis RJ, et al: Comparison of clinical outcomes of 1- and 2-level total disc replacement: four-year results from a prospective, randomized, controlled, multicenter IDE clinical trial. Spine (Phila Pa 1976) 40:759-766, 2015

3. Cardoso MJ, Rosner MK: Multilevel cervical arthroplasty with artificial disc replacement. Neurosurg Focus 28(5):E19, 2010

4. Cheng L, Nie L, Zhang L, Hou Y: Fusion versus Bryan Cervical Disc in two-level cervical disc disease: a prospective, randomised study. Int Orthop 33:1347-1351, 2009

5. Cho BY, Lim J, Sim HB, Park J: Biomechanical analysis of the range of motion after placement of a two-level cervical ProDisc-C versus hybrid construct. Spine (Phila Pa 1976) 35:1769-1776, 2010

6. Cunningham BW, Hu N, Zorn CM, McAfee PC: Biomechanical comparison of single- and two-level cervical arthroplasty versus arthrodesis: effect on adjacent-level spinal kinematics. Spine J 10:341-349, 2010

7. Davis RJ, Nunley PD, Kim KD, Hisey MS, Jackson RJ, Bae $\mathrm{HW}$, et al: Two-level total disc replacement with Mobi-C cervical artificial disc versus anterior discectomy and fusion: a prospective, randomized, controlled multicenter clinical trial with 4-year follow-up results. J Neurosurg Spine 22:15-25, 2015

8. Fay LY, Huang WC, Tsai TY, Wu JC, Ko CC, Tu TH, et al: Differences between arthroplasty and anterior cervical fusion in two-level cervical degenerative disc disease. Eur Spine J 23:627-634, 2014

9. Goffin J, van Loon J, Van Calenbergh F, Lipscomb B: A clinical analysis of 4- and 6-year follow-up results after cervical disc replacement surgery using the Bryan Cervical Disc Prosthesis. J Neurosurg Spine 12:261-269, 2010

10. Huppert J, Beaurain J, Steib JP, Bernard P, Dufour T, Hovorka I, et al: Comparison between single- and multi-level patients: clinical and radiological outcomes 2 years after cervical disc replacement. Eur Spine J 20:1417-1426, 2011

11. Kim HK, Kim MH, Cho DS, Kim SH: Surgical outcome of cervical arthroplasty using Bryan ${ }^{\circledR}$. J Korean Neurosurg Soc 46:532-537, 2009

12. Kim SW, Limson MA, Kim SB, Arbatin JJ, Chang KY, Park MS, et al: Comparison of radiographic changes after ACDF versus Bryan disc arthroplasty in single and bi-level cases. Eur Spine J 18:218-231, 2009

13. Liu H, Liu X, Shi R: [Two-level cervical artificial disc replacement combined with nearby segments fused for multilevel disc herniations.] Zhongguo Xiu Fu Chong Jian Wai Ke Za Zhi 20:383-386, 2006 (Chinese)

14. Martin S, Ghanayem AJ, Tzermiadianos MN, Voronov LI, Havey RM, Renner SM, et al: Kinematics of cervical total disc replacement adjacent to a two-level, straight versus lordotic fusion. Spine (Phila Pa 1976) 36:1359-1366, 2011

15. Nilsson OS, Persson PE: Heterotopic bone formation after joint replacement. Curr Opin Rheumatol 11:127-131, 1999

16. Pimenta L, McAfee PC, Cappuccino A, Cunningham BW, Diaz R, Coutinho E: Superiority of multilevel cervical arthroplasty outcomes versus single-level outcomes: 229 consecutive PCM prostheses. Spine (Phila Pa 1976) 32:13371344, 2007

17. Radcliff K, Coric D, Albert T: Five-year clinical results of cervical total disc replacement compared with anterior discectomy and fusion for treatment of 2-level symptomatic degenerative disc disease: a prospective, randomized, controlled, multicenter investigational device exemption clinical trial. J Neurosurg Spine 25:213-224, 2016

18. Ritter MA, Sieber JM: Prophylactic indomethacin for the prevention of heterotopic bone formation following total hip arthroplasty. Clin Orthop Relat Res (196):217-225, 1985

19. Robertson JT, Metcalf NH: Long-term outcome after implantation of the Prestige I disc in an end-stage indication: 4-year results from a pilot study. Neurosurg Focus 17(3):E10, 2004

20. Safavi-Abbasi S, Reyes PM, Abjornson C, Crawford NR: Feasibility and biomechanics of multilevel arthroplasty and combined cervical arthrodesis and arthroplasty. Clin Spine Surg 29:E522-E531, 2016

21. Sekhon LH: Two-level artificial disc placement for spondylotic cervical myelopathy. J Clin Neurosci 11:412-415, 2004

22. Sekhon LH, Sears W, Duggal N: Cervical arthroplasty after previous surgery: results of treating 24 discs in 15 patients. $\mathbf{J}$ Neurosurg Spine 3:335-341, 2005

23. Tu TH, Wu JC, Huang WC, Guo WY, Wu CL, Shih YH, et al: Heterotopic ossification after cervical total disc replacement: determination by CT and effects on clinical outcomes. J Neurosurg Spine 14:457-465, 2011

24. Wu JC, Huang WC, Tsai TY, Fay LY, Ko CC, Tu TH, et al: Multilevel arthroplasty for cervical spondylosis: more heterotopic ossification at 3 years of follow-up. Spine (Phila Pa 1976) 37:E1251-E1259, 2012

25. Zhao H, Cheng L, Hou Y, Liu Y, Liu B, Mundra JJ, et al: Multi-level cervical disc arthroplasty (CDA) versus singlelevel CDA for the treatment of cervical disc diseases: a metaanalysis. Eur Spine J 24:101-112, 2015

26. Zhao Y, Zhang Y, Sun Y, Pan S, Zhou F, Liu Z: Application of cervical arthroplasty with Bryan cervical disc: 10-year follow-up results in China. Spine (Phila Pa 1976) 41:111115,2016

\section{Disclosures}

Dr. Riew reports that he receives personal fees from Biomet and Medtronic Sofamor Danek. He also has direct stock ownership in the following companies: Osprey, Medyssey, Expanding Orthopedics, Spineology, Spinal Kinetics, Nexgen Spine, Amedica, Vertiflex, Benvenue, Paradigm Spine, and PSD.

\section{Author Contributions}

Conception and design: both authors. Acquisition of data: Joaquim. Analysis and interpretation of data: both authors. Drafting the article: both authors. Critically revising the article: both authors. Reviewed submitted version of manuscript: both authors. Approved the final version of the manuscript on behalf of both authors: Joaquim. Study supervision: Riew.

\section{Correspondence}

Andrei F. Joaquim, Department of Neurology, Discipline of Neurosurgery, Universidade Estadual de Campinas, Rua: Tessália Vieira de Camargo, 126, Campinas SP 13083-887, Brazil. email: andjoaquim@yahoo.com. 